\title{
Upgrading Methylation Method for Structural Studies of Polysaccharides: Case Analysis of a Bioactive Polysaccharide from Acacia tortilis
}

\author{
Shipra Nagar ^, Ajeet Kumar Lakhera and Vineet Kumar* \\ Chemistry \& Bio-Prospecting Division, Forest Research Institute, Dehradun 248006, India
}

Received 27 April 2020; accepted in revised form 08 May 2020

\begin{abstract}
Methylation has been the most widely used conventional tool in the structural characterization of polysaccharides. In the series of developments in methylation methods a diverse range of solvents and methylating reagents under basic conditions, the main emphasis relied upon inclusive solubilization of polysaccharides during the reaction procedure. In our laboratory, Acacia tortilis ssp. raddiana (Savi) Brenan polysaccharide (AcTP) has been reported for antidiabetic activity and hence its chemical structure has been investigated. AcTP was found to be composed of L-rhamnose, L-arabinose, D-mannose, D-galactose, Dgalacturonic acid, and D-glucuronic acid in molar ratio 1:34:1:10:2:2 respectively. The polysaccharide was subjected to Hakomori methylation protocol for linkage analysis. However, the method encountered following limitations: undermethylation, partial degradation of polysaccharide, and decline in solubility of methylated product in hydrolytic and reducing reagents for further derivatization to partially methylated alditol acetates (PMAA). The limitations were circumvented by applying key modifications in standard protocol viz. in situ production of methylsulfinyl methyl sodium; purification of a product by dialysis; replacing $0.15 \mathrm{M} \mathrm{H}_{2} \mathrm{SO}_{4}$ by $4 \mathrm{M}$ trifluoroacetic acid and performing the reduction by $\mathrm{NaBH}_{4}$ in methanol/chloroform (7:3) solvent system. Therefore, permethylation of AcTP to PMAA was realized by the proposed modified method and glycosyl linkages were studied by GC-MS. The monosaccharide composition based on alditol acetate investigation and successive PMMA analysis demonstrated complete methylation signifying the worthiness of the modified method. The methylation was also confirmed by FTIR results. Unlike the original protocol, the modified method is more feasible, efficient, and effective $\Lambda^{\text {can }}$ be used for permethylation of neutral as well as acidic polysaccharides.
\end{abstract}

Keywords: Acacia tortilis, structural characterization, polysaccharide, modification.

\section{Introduction}

In view of the obvious role of gum exudates and other important polysaccharides in the global bio-economy, their structural characterization is an essential prerequisite to understand the structure-activity relationship and subsequent structural modifications for diverse applications. Methylation analysis is the most extensively used method in carbohydrate chemistry and has been practiced for numerous decades in the structural investigation of polysaccharides. It is primarily used to study the nature and position of glycosidic linkages among constituent monosaccharides and thus it is a very helpful technique for structural analysis ${ }^{1}$. Per-alkylation is preferred over other derivatizations (e.g. per-acetylation, per-silylation) since the ether bonds formed thereafter are stronger than the glycosidic linkages and hence stable under acidic conditions during hydrolysis ${ }^{2}$. There are several methods ${ }^{1,3-12}$ for

$\wedge$ Present address: National Centre for Polar and Ocean Research, Ministry of Earth Sciences, Goa, India 
methylation of oligosaccharides and polysaccharides in aqueous and non-aqueous media. Methylation technique was first proposed by Purdie and Irvine, $1903^{3}$ by employing methanol, silver oxide, and methyl iodide; however, it did not work due to the reaction of methyl iodide with methanol. Further, acetone, being inert to MeI, was used but the former has lower polysaccharide solubilizing ability than methanol. Hence, the method was limited to methylation of non-reducing glycosides as silver oxide oxidizes the reducing sugars to esters.

Consequently, the method was modified by Haworth, $1915^{4}$ using dimethyl sulfate and $50 \%$ $\mathrm{NaOH}$. However, in several cases, the method suffered from a low degree of substitution and higher polysaccharide degradation i $\lambda$ harsh alkaline conditions leading to lower recovery. Further, Kuhn et al.,1955 ${ }^{5}$ and Wallenfels et al., 1963 ${ }^{6}$ proposed methylation by taking polysaccharide in dimethylformamide (DMF) ${ }^{5,7,8}$, or DMSO ${ }^{9}$ and treating with dimethyl sulfate in presence of $\mathrm{BaO}$ or $\mathrm{Ba}(\mathrm{OH})_{2}$ to make the procedure more effective. Later, silver oxide was replaced by $\mathrm{Al}_{2} \mathrm{O}_{3}$. The use of non-oxidizing metal oxide in DMF increased the yield of methylated products in comparison with modified Purdie's reagent however, the quest for solubilizing the polysaccharide insolvent before reaction had still not been completely resolved. Subsequently, Falconer and Adams, $1956{ }^{10}$ proposed methylation using dimethyl sulfate and solid $\mathrm{NaOH}$ in tetrahydrofuran (THF). The method was also inadequate due to the insolubility of polysaccharides in THF. Barker et al., $1959^{11}$, proposed liquid ammonia-sodiummethyl iodide method of methylation, wherein, polysaccharide was swollen in liquid ammonia, followed by addition of sodium and methyl iodide. However, the procedure is extremely sensitive as sodamide formed during reaction causes extensive degradation of the polysaccharide. Srivastava et al., $1964{ }^{12}$ proposed modification in Falconer and Adams ${ }^{10}$ method using dimethyl sulfate and $\mathrm{NaOH}$ pellets in dimethyl sulphoxide. Subsequently, Hakomori ${ }^{1}$ in 1964 proposed a modified methylation protocol employing DMSO and dimsyl sodium as base and methyl iodide as a methylating agent. The dimsyl ion is generated by treating sodium hydride $(\mathrm{NaH})$ with DMSO.
However, $\mathrm{NaH}$ being highly reactive may ignite in air to produce inflammable $\mathrm{H}_{2}$ gas. Therefore, it is preserved in mineral oil, hove the oil acted as a source of impurities in the chromatogram of partially methylated alditol acetates (PMAA) ${ }^{13}$. Further, butyllithium was used as a substitute to $\mathrm{NaH}$, giving lithiummethylsulfinylcarbanion as a precursor to methylation ${ }^{14,15}$. Ciucanu and Kerek ${ }^{16}$ in 1984, while working on Srivastava et al.1964 ${ }^{12}$ method, also proposed the use of solid $\mathrm{NaOH}$ or $\mathrm{KOH}$ in $\mathrm{t}-\mathrm{BuOH}$ as $\Lambda_{\Lambda}$ comparatively mild $\Lambda_{\text {base }}$ to reduce the degradation of the polymer.

In the series of developments in methylation methods over decades, the main emphasis relied upon inclusive solubilization of polysaccharides during the reaction procedure such that free hydroxyls are per-methylated to achieve accurate linkage information. Despite the development of several methylation methods and their subsequent modifications, Hakomori method ${ }^{1}$ is still the most widely used protocol for methylation of carbohydrates ${ }^{17-19}$, wherein, DMSO and dimsyl sodium (methylsulfinyl methyl sodium) are used as the base, resulting in the formation of polyalkoxide ion of the substrate, which is a critical step. Etherification is then achieved by methyl iodide. In case of polysaccharides, partial solubility may prevent complete methylation in one step. Hence the usual approach is to obtain a partially methylated polymer in the first step, which would eventually have lower polarity and higher solubility in methylating reaction mixture, thereby, leading to a higher degree of alkylation. The limitation in complete $O$-methylation is due to the steric hindrance of the polysaccharide possessing a 3-dimensional structure, wherein hydroxyl groups are highly restricted with intra- and inter molecular hydrogen bonding.

In the present investigation, Acacia tortilis polysaccharide (AcTP) from the gum exudates was taken as a case study. The studies carried out in our laboratory conclusively reported $A$. tortilis polysaccharide as a good in vitro $\alpha$-glucosidase inhibitor and showed inhibition against Saccharomyces cerevisiae yeast as well as mammalian intestinal $\alpha$-glucosidase $\Lambda_{\Lambda}^{21}$. Intriguingly, due to lack of structural information, the polysaccharide is underrated and underutilized. Hence, it was decided to investigate the structure of AcTP by 
Hakomori methylation procedure. However, during the study, the method encountered limitations such as undermethylation, partial degradation, loss of material, and decline in solubility of methylated polysaccharide in hydrolytic and reducing reagents for further derivatization to PMAA. The above limitations were extensively studied and circumvented based on modified experimental protocol developed in a laboratory. Hence, this manuscript aims to provide the technical details and critical procedural steps necessary for successful methylation.

\section{Materials and methods \\ Materials}

The sample of $A$. tortilis ssp. Raddiana (Sabi) Brenan gum exudate was provided by Central Arid Zone Research Institute (CAZRI), Jodhpur research farm under the network project on 'Harvesting, processing and value addition of Natural Resins and Gums'. The material was authenticated and verified by Dr. J. C. Tewari, Principal Scientist (Forestry), CAZRI, Jodhpur, India.

\section{General methods of analysis}

If not stated otherwise, all chemicals were of analytical grade, purchased from Merck India. 3,5- dimethylphenol and all monosaccharide standards viz: L-arabinose, D-glucose, D-galactose, L-rhamnose, D-mannose, D-glucuronic acid and D-galacturonic acid were purchased from SigmaAldrich (St. Louis, MO, USA). All the experiments were performed in triplicate to minimize experimental error. Gel permeation chromatography (GPC) was performed using Sephadex G200, packed in the Pharmacia column [C56/70] and fractions were collected using Gilson fraction collector-201 and HP2 mini plus pump. Highperformance size exclusion chromatography (HPSEC) was performed on the Waters-HPSEC system. The system contained Waters binary HPLC pump (1525) with in-line degasser attached to waters SEC column (HSP Gel AQ-MB-H) coupled with Waters refractive index detector (2414). The colorimetric tests were performed on Chemito UV-Vis Spectrophotometer UV-2500 at different wavelengths. Gas-liquid chromatography was carried out on Thermo Scientific gas chromatograph GC-600 fitted with a flame ion- ization detector (FID) and BPX70 capillary column under the following operating conditions: single ramp program with initial temperature $190^{\circ} \mathrm{C}$ (1 min hold) with an increase of $3^{\circ} \mathrm{C} / \mathrm{min}$ to reach final temperature $260^{\circ} \mathrm{C}(10 \mathrm{~min}$ hold $)$ with a Nitrogen flow rate of $1.5-2.0 \mathrm{~mL} / \mathrm{min}$. The GC-MS analyses were performed on a 7890B gas chromatograph coupled with 5977A mass spectrometer, equipped with electron ionization (EI) and quadrupole analyzer (Agilent Technologies, Santa Clara, CA, USA). Samples were loaded in $1 \mu \mathrm{L}$ injection volume and eluted from RTX 2330 (Restek) column using helium as carrier gas at a flow rate of $1.2 \mathrm{~mL} / \mathrm{min}$. The operating conditions were as follows: single ramp program with injection port temperature $250^{\circ} \mathrm{C}$; initial column temperature- $190^{\circ} \mathrm{C}(1 \mathrm{~min}$ hold $)$ with an increase of $3^{\circ} \mathrm{C} / \mathrm{min}$ to reach final temperature $240^{\circ} \mathrm{C}(5$ min hold); GC-MS Transfer Line Temp, $280^{\circ} \mathrm{C}$; MS Source: $230^{\circ} \mathrm{C}$; MS Quad: $150^{\circ} \mathrm{C}$.

\section{Isolation and purification of polysaccharide}

The polysaccharide was isolated by standard protocol ${ }^{22}$ that involves the dissolution of exudate samples in distilled water followed by precipitation. Briefly, the crude gum sample (10 g) was milled and dissolved in a minimum amount of water $(60 \mathrm{ml})$. The solution was filtered through a sintered glass filter (G1) to remove water insoluble impurities $(0.38 \mathrm{~g})$ and give a clear paleyellow filtrate. To this solution, three folds of acetone $(180 \mathrm{ml})$ was added with continuous stirring and left overnight at $4{ }^{\circ} \mathrm{C}$. After a period of $10 \mathrm{~h}$, the white fluffy settled layer was recovered by centrifugation (10 min, $2000 \mathrm{rpm}$ ) to give a white precipitate, which was freeze-dried to yield crude polysaccharide $(6.7 \mathrm{~g}, 67 \%)$.

The isolated crude polysaccharide was purified by re-precipitation and ion exchange chromatography ${ }^{23}$. In brief, the polysaccharide was dissolved in water and re-precipitated with acetone. The precipitate was washed several times with acetone and ether and dried in a vacuum desiccator. The re-precipitated polysaccharide solution $(200 \mathrm{mg} /$ $\mathrm{mL}$ ) was de-ionized by successively passing through the columns of the freshly regenerated cation (Dowex-50 W-X8) and anion (SeraliteSRA-400) exchange resins. In both the experiments, after sample elution, columns were washed 
until the eluted solution showed a negative 'Molisch test'. The de-ionized polysaccharide solution was concentrated ( $1 / 4^{\text {th }}$ volume) and dialyzed using the dialysis membrane of MWCO 12$14 \mathrm{kDa}$ against distilled water for $72 \mathrm{~h}$. The dialyzed product was lyophilized to obtain the pure AcTP in the form of a white amorphous powder (4.69 g, $46.9 \%$ ).

\section{Homogeneity of polysaccharide}

AcTP solution $(20 \mathrm{mg} / \mathrm{mL})$ was loaded on GPC column and 80 fractions were collected with fraction size of $2 \mathrm{~mL}$. Each fraction was tested for polysaccharide content by anthrone-sulphuric acid test ${ }^{24}$, wherein, $200 \mu \mathrm{L}$ of eluent of each fraction was treated with anthrone-sulphuric acid reagent and absorption was measured at $620 \mathrm{~nm}$. A graph of absorbance versus the number of fractions was plotted (Figure 1). The fractions 28 to 31 illustrating a single peak were combined, concentrated to a small volume and precipitated by ethanol. The precipitated polysaccharide was filtered, lyophilized and used for further study. The homogeneity of polysaccharide was further confirmed by HP-SEC. The sample was dissolved in HPLC grade water $(1.0 \mathrm{mg} / \mathrm{mL}$ and $0.05 \mathrm{mg} / \mathrm{ml})$ and filtered through a $0.45 \mu \mathrm{m}$ filter. It was then loaded $(20 \mu \mathrm{l})$ via a manual injection port system and eluted with HPLC grade water with a flow rate of $0.4 \mathrm{ml} / \mathrm{min}$.

\section{Neutral monosaccharide composition}

AcTP (10 mg) was hydrolyzed by $2 \mathrm{M}$ trifluoroacetic acid (TFA, $5 \mathrm{~mL}$ ) at $100^{\circ} \mathrm{C}$ for 4 h. TFA was removed under stream of dry nitrogen to give dry mass. The hydrolyzates obtained were reduced with a $0.25 \mathrm{M}$ sodium borohydride solution at $60^{\circ} \mathrm{C}$ for $2 \mathrm{~h}$. Boric acid (a by-product of reduction) was removed by co-distillation with acetic acid-methanol (15\%, $5 \mathrm{ml}, 3$ times) followed by washing with methanol $(5 \mathrm{ml})$ to yield a dry mass. The alditol mixture was acetylated with acetic anhydride $(1 \mathrm{ml})$ and pyridine $(250$ $\mu \mathrm{l})$, at $90^{\circ} \mathrm{C}$ for $2 \mathrm{~h}$. The alditol acetates were extracted with dichloromethane (DCM) and washed with saturated solution of sodium bicarbonate, 0.1 $\mathrm{M} \mathrm{HCl}$, and water. The DCM layer was dried over activated sodium sulfate and concentrated. The alditol acetates of standards and samples were subjected to GLC analysis ${ }^{25}$.

\section{Acidic monosaccharide composition} Spectrophotometric quantification of uronic acid

The presence of uronic acids was determined qualitatively and quantitatively by 3,5-dimethyl phenol method ${ }^{26}$. The method facilitates independent estimation of glucuronic as well as galacturonic acids. Method A (for galacturonic acid): Sample containing $0.125 \mathrm{~mL}$ of AcTP solution $(100 \mu \mathrm{g} / \mathrm{mL})$ and $0.125 \mathrm{~mL}$ of $2 \% \mathrm{NaCl}$ was treated with $2 \mathrm{~mL}$ conc. sulfuric acid followed by vortexing. The mixture was heated at $70^{\circ} \mathrm{C}$ for 10 minutes, cooled at room temperature, followed by the addition of $0.1 \mathrm{~mL} \mathrm{3,5-dimethylphenol}$ solution (0.1g 3,5-dimethyl phenol in $100 \mathrm{ml}$ glacial acetic acid) and absorbance was instantly measured after vortexing at $450 \mathrm{~nm}$ and $400 \mathrm{~nm}$. Galacturonic acid standards of varying concen-

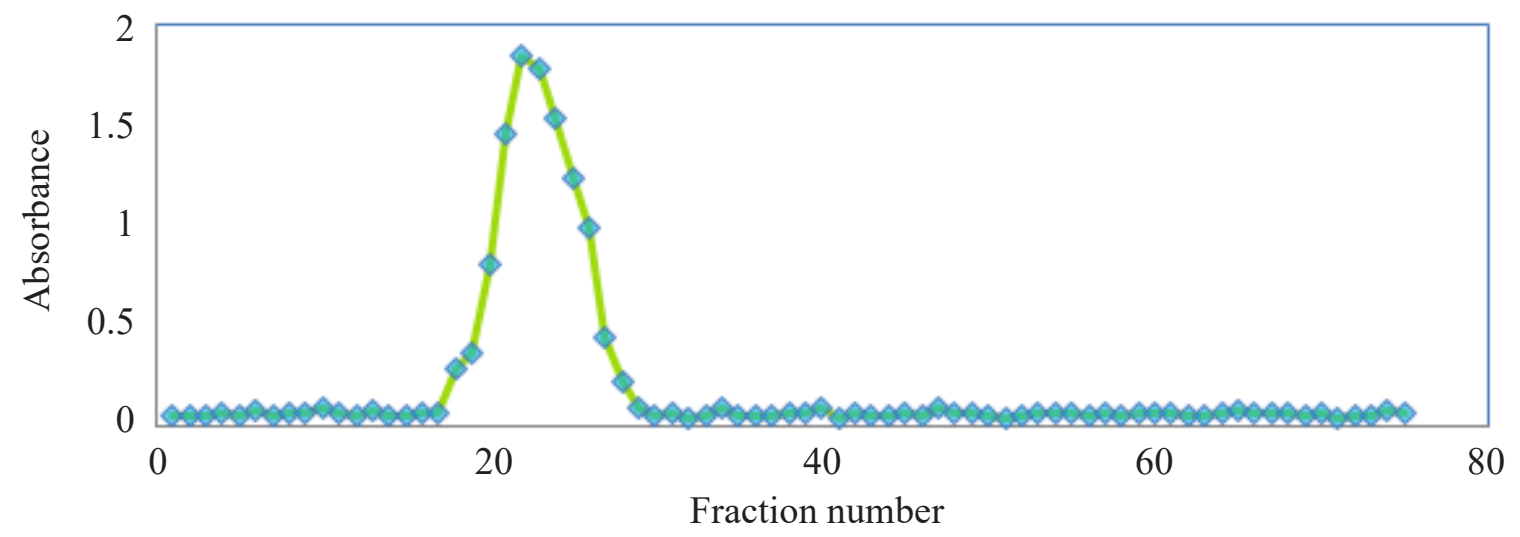

Figure 1. Gel permeation chromatography elution pattern of AcTP Polysaccharide 
trations $(20-80 \mu \mathrm{g} / \mathrm{mL})$ were prepared and their absorptivity values were multiplied by correction factor 1.12 to obtain a calibration curve, which was then used to estimate uronic acid content in a sample. Method B for glucuronic acid quantification was similar to method A except for two differences. The $2 \% \mathrm{NaCl}$ solution was replaced by $\mathrm{NaCl}-\mathrm{H}_{3} \mathrm{BO}_{4}(2 \mathrm{~g} \mathrm{NaCl}$ and $3 \mathrm{~g}$ boric acid dissolved in $100 \mathrm{~mL}$ water) solution and the time of heating was $40 \mathrm{~min}$. The concentration of glucuronic acid was determined by subtracting the absorbance difference observed in method B from that of method A. The subtracted values were compared to the calibration curve of the glucuronic acid to provide the glucuronic acid content.

\section{Reduction of uronic acids}

The uronic acid present in polysaccharide was reduced by the method of Taylor and Conrad, $1972{ }^{27}$. AcTP solution $(10 \mathrm{mg} / \mathrm{mL})$ was acidified to $\mathrm{pH} 4.75$ and $1 \mathrm{mmol}$ of solid 1-ethyl-3-(3-dimethyl aminopropyl)carbodiimide (EDC) was added. The reaction proceeded for $45 \mathrm{~min}$ at $\mathrm{pH}$ 4.75 until the evolution of hydrogen ceased. 25 $\mathrm{mL}$ of $3 \mathrm{M} \mathrm{NaBH}_{4}$ was added drop wise at $25^{\circ} \mathrm{C}$ in the one hour while simultaneously maintaining the $\mathrm{pH}$ of reaction mixture 7.0 by the addition of $1 \mathrm{MHCl}$. The resultant mixture was then made slightly acidic to destroy the remaining $\mathrm{NaBH}_{4}$ if any. The solution was thoroughly dialyzed (12-14 kDa) against distilled water for $72 \mathrm{~h}$ and concentrated under reduced pressure to a small volume $(4 \mathrm{~mL})$. The reduced polymer was then precipitated by adding three volumes $(12 \mathrm{~mL})$ of ethanol, filtered and dried to give reduced polysaccharide (AcTPR, $0.076 \mathrm{~g}$ ). The complete reduction of uronic acid was confirmed by a negative carbazole-sulphuric acid color test. Alditol acetates of AcTPR were prepared in the same way as mentioned in section Neutral monosaccharide composition. The molar ratio of native and reduced polysaccharides was compared to give uronic acid contents.

\section{Methylation method \\ Standard methylation protocol}

Initially AcTP was subjected to standard methylation procedure ${ }^{1}$. In brief, methylsulfinyl methyl sodium base was prepared ex-situ by add- ing $30 \mathrm{~mL}$ dried dimethyl sulphoxide (DMSO) to $1.5 \mathrm{~g}$ of $57 \%$ suspension of sodium hydride in mineral oil mixed with $10 \mathrm{~mL}$ of anhydrous ether. The polysaccharide solution of DMSO $(5 \mathrm{mg} / \mathrm{mL})$ was treated with a $0.4 \mathrm{~mL}$ methylsulfinyl methyl sodium base followed by the addition of $0.3 \mathrm{~mL}$ dry methyl iodide and the reaction mixture was left for 1-6 h at room temperature. The methylated polysaccharide was extracted with $4 \mathrm{~mL}$ chloroform. The $\mathrm{CHCl}_{3}$ layer was washed with water and dried over anhydrous magnesium sulfate. The product was purified by column chromatography on Sephadex LH-20. The methylation process was repeated thrice and IR spectra of native and methylated polymer were recorded to confirm the per-etherification of free hydroxyl groups.

The methylated polymer was depolymerized by $90 \%$ formic acid at $105^{\circ} \mathrm{C}$ for $1.5 \mathrm{~h}$. Formic acid was removed and the product was hydrolysed by $0.15 \mathrm{M} \mathrm{H}_{2} \mathrm{SO}_{4}$ at $105^{\circ} \mathrm{C}$ for $12-18 \mathrm{~h}$ under inert conditions. The acid was neutralized by $\mathrm{BaCO}_{3}$ and $0.1 \mathrm{M} \mathrm{NaOH}$. The hydrolyzate mixture was reduced to alditols by solid $\mathrm{NaBH}_{4}$ for $12 \mathrm{~h}$ at room temperature. Excess of reducing agent was neutralized by Dowex $50\left(\mathrm{H}^{+}\right)$ion-exchange resin and the by-product was removed by co-distillation with methanol. The alditols were acetylated by $0.5 \mathrm{~mL}$ of equal parts of acetic anhydride and pyridine at $105^{\circ} \mathrm{C}$ for $2 \mathrm{~h}$ to give PMMA.

\section{Modified methylation protocol}

$5 \mathrm{~g}$ sodium hydride suspension $(60 \%$ in mineral oil) was washed with ether $(10 \mathrm{~mL} \times 3)$ and completely dried under a stream of nitrogen. The polysaccharide $(100 \mathrm{mg}$ ) was dissolved in $10 \mathrm{~mL}$ DMSO (dried over molecular sieve) in a threenecked flask, attached to the reflux condenser under regular nitrogen supply. The reaction mixture was heated at $55^{\circ} \mathrm{C}$ with continuous stirring and dried sodium hydride was added slowly during a period of $2 \mathrm{~h}$. After complete addition, the reaction mixture was stirred for the next $2 \mathrm{~h}$ at $55^{\circ} \mathrm{C}$ under nitrogen source until the evolution of hydrogen ceased. It was then cooled on an ice bath and $3 \mathrm{~mL}$ methyl iodide was added slowly. The reaction mixture was left for $18 \mathrm{~h}$ followed by further addition of $2 \mathrm{~mL}$ methyl iodide. The reaction was continued for the next $1 \mathrm{~h}$ and then 
quenched by adding $15 \mathrm{~mL}$ distilled water. It was dialyzed for $96 \mathrm{~h}$ against distilled water to remove residual DMSO, followed by fractionation with chloroform $(15 \mathrm{~mL}$ x 3$)$. The chloroform layer was washed thoroughly with distilled water to remove water-soluble impurities and traces of DMSO. The organic layer was dried over activated anhydrous sodium sulfate (30 min), filtered, and concentrated to syrup (70 mg). IR spectrum of the sample was recorded to check the absorption band in the $-\mathrm{OH}$ region $\left(3590-3225 \mathrm{~cm}^{-1}\right)$. The methylation process was repeated twice until -OH band completely disappeared.

Partially methylated alditol acetates (PMAA)

The methylated polysaccharide $(67 \mathrm{mg})$ was refluxed with $90 \%(\mathrm{v} / \mathrm{v})$ formic acid $(5 \mathrm{~mL})$ at $100^{\circ} \mathrm{C}$ for $1 \mathrm{~h}$ and excess of formic acid was evaporated in a rotary evaporator to dryness. The depolymerized methylated product was hydrolyzed by $4 \mathrm{M}$ TFA $(5 \mathrm{~mL})$ at $100^{\circ} \mathrm{C}$ for $6 \mathrm{~h}$ and acid was removed under a nitrogen stream. Completely dried hydrolyzates were solubilized in a mixture of methanolic chloroform (3:7) followed by the addition of $150 \mathrm{mg}$ sodium borohydride. The reaction mixture was kept for $18 \mathrm{~h}$ at room temperature. The resulting solution was neutralized by $2 \%$ methanolic acetic acid and boric acid (a by-product of reduction) was removed by repeated co-distillation with methanol $(3 \times 5 \mathrm{~mL})$ under reduced pressure. The partially methylated alditols were treated with acetic anhydride and pyridine, 1:1 (4 $\mathrm{mL})$ and the reaction mixture was refluxed for $6 \mathrm{~h}$. PMAA thus obtained were extracted with DCM $(4 \times 5 \mathrm{~mL})$. The organic layer was repeatedly washed with water and dried over anhydrous sodium sulfate. PMAA mixture of AcTP and AcTPR samples were subjected to GCMS analysis to give a molar ratio and linkage of constituting residues.

\section{Results and discussion}

Despite substantial literature available on methylation analyses discussing diverse approaches for etherification of carbohydrate polymer, no technique has been developed yet which could promise the permethylation of polysaccharides containing combinations of labile pentose and deoxy monosaccharides, mild hexoses and refrac- tory uronic acid and aminosugars in one attempt. The major inadequacy in methylation protocol is partial or poor solubility of polysaccharides in the reaction mixture, which may be due to polarity difference of solute and solvent; steric hindrance due to their 3-dimensional conformational structure of the polymer and/or presence of restricted intra- and inter-molecular H-bonding that obstructs the solvent access required for dissolution. Therefore successive modifications have been made to the series of methods developed; however, there are several technical aspects regarding the procedure being used accurately depending upon the specific characteristics of the polysaccharide and consequently demand careful attention and considerable experience to achieve complete methylation. It is worth mentioning that ensuring precise methylation of the polysaccharide before proceeding to subsequent steps is crucial to obtain reliable results. In the present communication, we have attempted to modify the existing methylation protocol to enable the dissolution of polysaccharide samples at different steps and extend the utility of protocol varying from neutral to acidic carbohydrate polymers.

The crude polysaccharide was obtained in 67 $\%$ yield, which has been reduced to $46.9 \%$ after purification by re-precipitation, ion-exchange chromatography; and dialysis. The $\mathrm{CHN}$ content of crude and pure polysaccharides were recorded and provided in Table 1. A meager fall in elemental composition has been observed after purification. AcTP was subjected to GPC as well as HPSEC analyses and the polymer was found to be homogenous. HP-SEC elution profile of AcTP has been indicated in figure 2 .

\section{Neutral and acidic monosaccharide composi- tion}

Native and reduced AcTP samples were hydrolyzed with TFA, converted to alditol acetates, and subjected to GLC analysis. Pinitol was used as an internal standard to examine the recovery of the polysaccharide sample. The constituent monomers were separated and identified based on retention time (RT) of standard monosaccharides. AcTP was found to be composed of L-rhamnose, L-arabinose, D-mannose and D-galactose. The uronic acids were reported to be galacturonic and 
Table 1. Yields and CHN analysis of Crude and Purified Polysaccharides

\begin{tabular}{|lcc|}
\hline Parameters & Crude polysaccharide(\%) & Purified polysaccharide (AcTP) (\%) \\
\hline Yield & 67.0 & 46.9 \\
Carbon & 42.5 & 40.8 \\
Hydrogen & 6.1 & 5.7 \\
Nitrogen & 1.9 & 1.7 \\
\hline
\end{tabular}

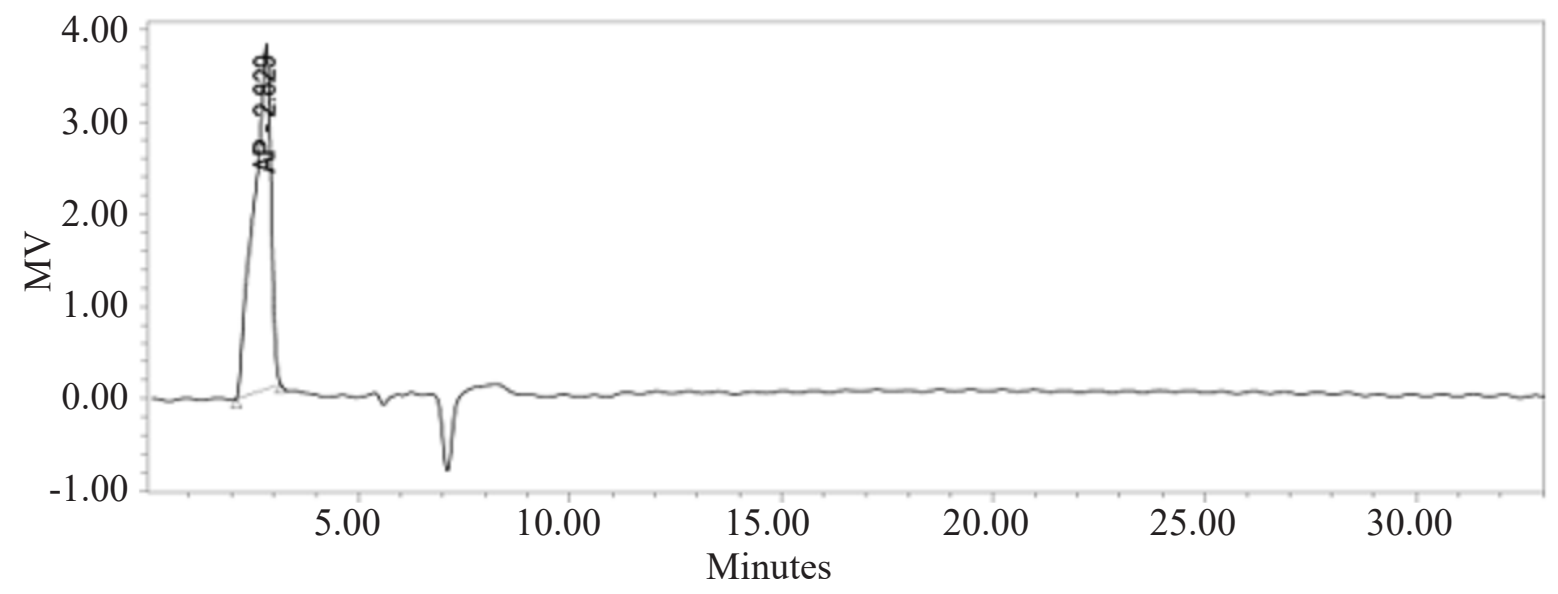

Figure 2. HP-SEC elution profile of AcTP polysaccharide

glucuronic acids, which were reduced to give two corresponding peaks, RT of which was coinciding with that of galactose and glucose respectively in GLC chromatogram. Alditol acetate studies revealed the recovery of $68.5 \%$ of the sample. The detailed monosaccharide composition of native and reduced AcTP is given in table 2. The spectrophotometric studies ascertained the presence of galacturonic acid and glucuronic acid in a molar percent of $4.29 \%$ and $4.96 \%$ respectively.

\section{Methylation analysis}

The purpose of methylation analysis is determination of linkage of constituent monomers. Methylation involves the introduction of methyl groups at all free hydroxyl groups that are not engaged in glycosidic linkage or attached to any other substituent, to produce the etherified product. The permethylated polysaccharide thus obtained is hydrolyzed to give partially methylated monosaccharides containing free hydroxyl group at sites which were earlier involved in linkage. The monomers are then reduced and acetylated to form partially methylated alditol acetates (PMAA), which are separated and characterized by GC-MS to provide complete information about the linkages between constituent monosaccharides. In methylation protocol, polysaccharides are treated with base to produce alkoxide ions that react with methyl iodide to give methylated polymer (Figure 3).

\section{Standard methylation protocol}

AcTP sample was subjected to methylation employing standard protocol ${ }^{1,28 ;}$ and the sample was found to be undermethylated even after three subsequent methylations and the consequent recovery of the product was less (36\%). The IR spectra of native polysaccharide and its methylated counterparts have been illustrated in figure 4 (A, B, C, D).

\section{Limitations in standard methylation protocol}

The standard method encountered several demerits. Firstly, undermethylated polysaccharide was obtained even after three successive methylations of the sample. Secondly partial degradation of the polysaccharide has been observed that resulted in subsequent loss of the material. Thirdly, when undermethylation and partial deg- 


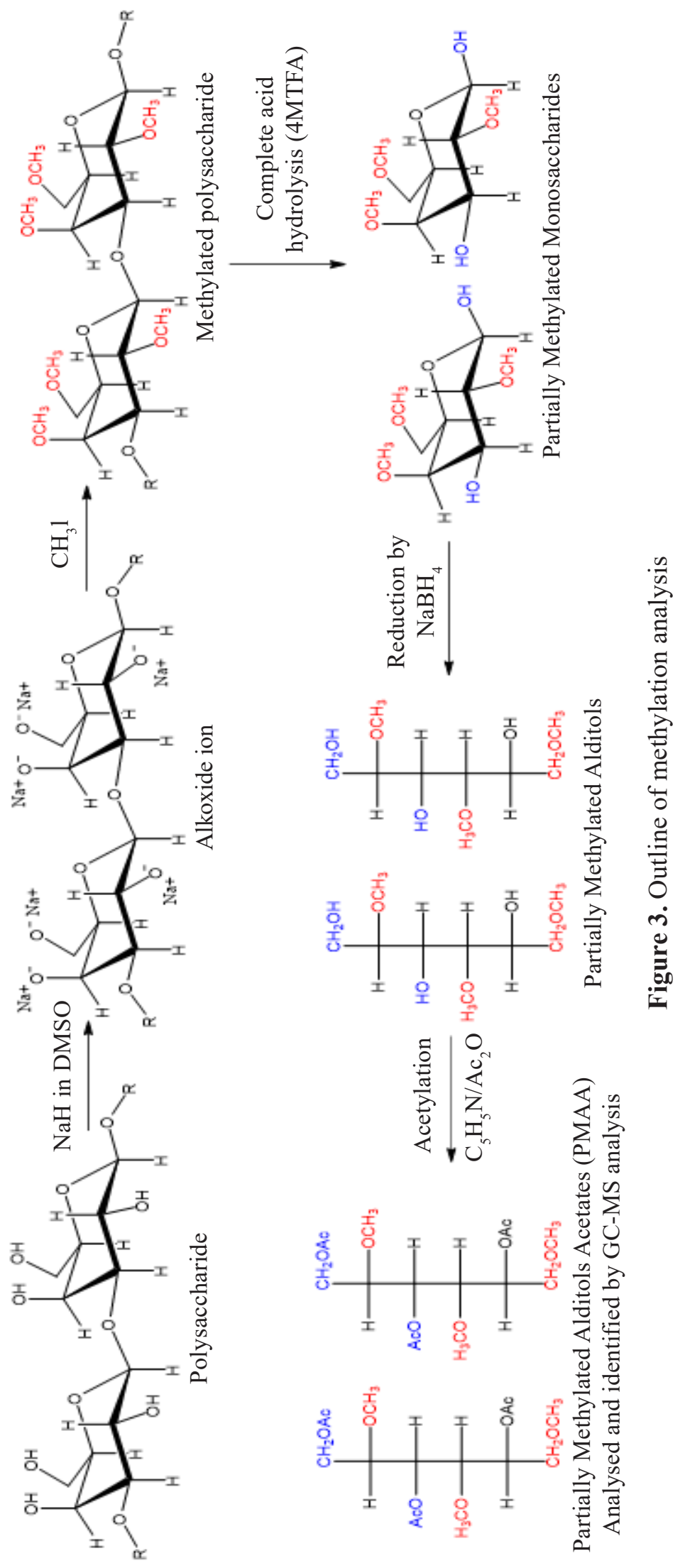



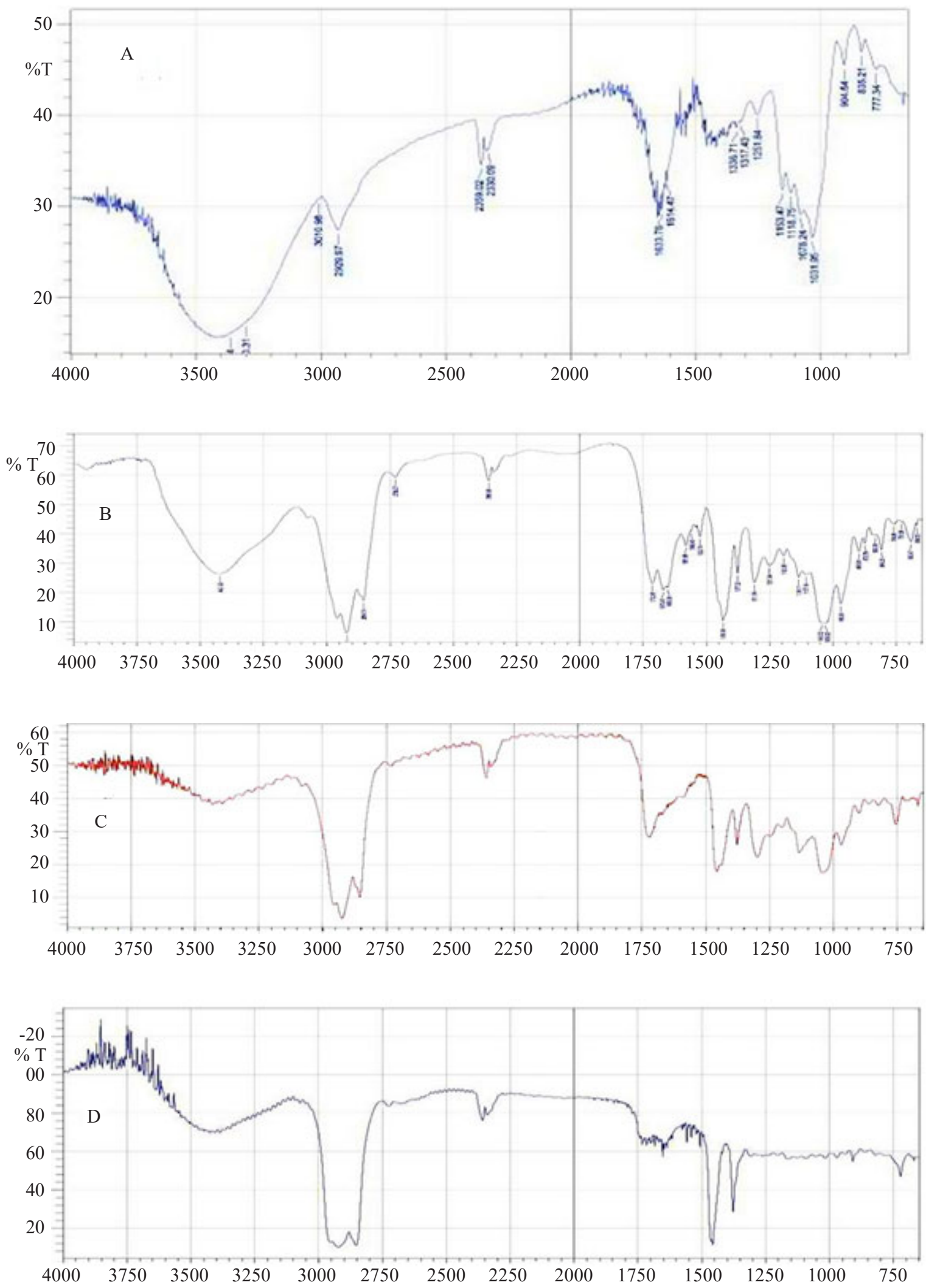

Figure 4. Methylation with Standard Method: A native polysaccharide; B one-time methylated; C two-times methylated; D three-times methylated polysaccharide. 
2. Monosaccharide composition of native and reduced AcTP polysaccharide

\begin{tabular}{|c|c|c|c|c|c|}
\hline \multirow[b]{2}{*}{$\Lambda^{\text {No. }}$} & \multirow[b]{2}{*}{ Monosaccharides } & \multicolumn{4}{|c|}{$\begin{array}{c}\text { Molar ratio of monosaccharides } \\
\text { in polysaccharide }\end{array}$} \\
\hline & & Retention time (min) & Native & Reduced & Difference \\
\hline 1 & Rhamnose & 4.18 & 1 & 1 & - \\
\hline 2 & Arabinose & 5.71 & 34 & 34 & - \\
\hline 3 & Mannose & 9.65 & 1 & 1 & - \\
\hline 4 & Galactose & 10.44 & 10 & 12 & 2 \\
\hline 5 & Glucose & 11.24 & - & 2 & 2 \\
\hline
\end{tabular}

radation occurred simultaneously during the reaction, under/un-methylated degraded parts of the polymer owing to higher polarity, could not be extracted by chloroform, thereby dwindling the yield as well as structural information enly of the part polysaccharide which is extracted in an organic solvent. Fourthly, methylated polysaccharide obtained thereafter, was found to have poor solubility in $0.15 \mathrm{M} \mathrm{H}_{2} \mathrm{SO}_{4}$ and aqueous $\mathrm{NaBH}_{4}$ reagents due to a sudden fall in the polarity of biopolymer by etherification. Hence partial dissolution of the sample resulted in incomplete hydrolysis as well as reduction. Such limitations lead to incomplete methylation and curtail the information required for the structural characterization of polysaccharide.

\section{Subsequent modifications in standard pro- tocol}

The limitations illustrated by standard methylation protocol were studied and subsequent modifications were introduced in the method as follows:

\section{a) In situ production of methylsulfinyl methyl sodium}

In the present protocol, methylsulfinyl methyl sodium has been prepared in the same reaction flask containing polysaccharide sample.

\section{Explanation}

The problem of undermethyaltion was analyzed and it was found that ex situ production of methylsulfinyl methyl sodium by reacting sodium hydride with DMSO in a separate flask, is unstable and undergoes rapid degradation in the presence of moisture and atmospheric $\mathrm{CO}_{2}{ }^{29}$. When the base (dimsyl ion) underwent degradation before its action, all the free hydroxyl groups were not converted to alkoxide ions, thereby leading to undermethylation. The solution to this problem was found to be in situ production of methylsulfinylmethyl sodium, so that as soon as dimsyl ion was formed, it reacted with free hydroxyl groups to form alkoxide ions.

\section{b) Independent successive methylations}

Sequential methylations were carried out independently i.e. after $1^{\text {st }}$ methylation, the product was purified and then subjected to $2^{\text {nd }}$ methylation.

\section{Explanation}

It has been mentioned in the literature ${ }^{30,31}$ that one can carry out successive methylations of the sample in the same reaction flask using repeated amounts of dimsyl ions and $\mathrm{CH}_{3} \mathrm{I}$. However, it was found that higher amounts of these methylating reagents in the presence of DMSO may lead to the formation of sodium iodide, dimethylmethoxysulphonium salt ${ }^{29}$, and other byproducts that subsequently decrease the rate of methylation. To reduce the formation of these side products, successive independent methylations were performed.

c) Purification of methylated product by dialysis

The methylated product was thoroughly dialyzed with a membrane of MWCO $3.5 \mathrm{kDa}$ against distilled water for 96 hours. 


\section{Explanation}

The extraction of the methylated product by chloroform has two implications. Firstly, in the event of simultaneous occurrence of undermethylation as well as partial degradation or peeling (in case polysaccharide contains neutral monosaccharides with reducing ends), chloroform may extract only methylated fraction of the polymer, while rest may remain in the reaction mixture. Secondly, DMSO being completely miscible in chloroform can be easily extracted along with polymer. Accordingly, it was observed from experimentation that several washings of chloroform layer with water did not aid incomplete removal of DMSO from the solution. These difficulties were circumvented by dialyzing the methylated product that facilitated the removal of $\mathrm{CH}_{3} \mathrm{I}$, DMSO, and other by-products as well as the conservation of polysaccharide (methylated or under methylated) sample. The same has been supported by literature ${ }^{32,33}$. The dialyzed product was subjected to chloroform extraction.

d) Replacing $0.15 \mathrm{M} \mathrm{H}_{2} \mathrm{SO}_{4}$ by $4 \mathrm{M}$ Trifluoroacetic acid (TFA)

The methylated polysaccharide was hydrolyzed by $4 \mathrm{M} \mathrm{TFA}\left(100^{\circ} \mathrm{C}, 6 \mathrm{~h}\right)$ instead of $0.15 \mathrm{M} \mathrm{H}_{2} \mathrm{SO}_{4}$ $\left(105^{\circ} \mathrm{C}, 12-18 \mathrm{~h}\right)$

\section{Explanation}

The methylated polysaccharide was not soluble in $0.15 \mathrm{M} \mathrm{H}_{2} \mathrm{SO}_{4}$ even after depolymerization with $90 \%$ formic acid. The reason behind such insolubility may be the difference in polarity of mineral acid and alkylated polysaccharide as well as the extent of depolymerization occurred. On the contrary, $4 \mathrm{M}$ TFA being an organic acid could easily solubilize and hence hydrolyze the etherified bio- polymer even without any prior depolymerization.

\section{e) Taking the reducing agent $\mathrm{NaBH}_{4}$ in metha- nol/chloroform mixture}

The hydrolyzate mixture was dissolved in a solvent system of methanol: chloroform (7:3) and then $\mathrm{NaBH}_{4}$ was added to the solution.

\section{Explanation}

It was observed that the hydrolyzate mixture (obtained after hydrolysis with $0.15 \mathrm{M} \mathrm{H}_{2} \mathrm{SO}_{4}$ ) was not soluble in an aqueous solution of sodium borohydride due to differences in polarity. Under this condition, a mixture of methanol: chloroform in ratio 7:3 was taken to solubilize the hydrolyzates, followed by the addition of $\mathrm{NaBH}_{4}$. The technique aided incomplete reduction. It is advised to use $\mathrm{NaBD}_{4}$ instead of $\mathrm{NaBH}_{4}$ that would make it easier to identify the head and tail of PMAA residues in GC-MS analysis.

\section{Modified methylation protocol}

AcTP was subjected to modified methylation protocol as discussed previously in section "Subsequent Modifications" in Standard Protocol and the method yielded permethylated polysaccharide in higher yield (67\%) only after two successive methylations. The IR spectra of native polysaccharide and its methylated counterparts have been illustrated in figure 5 (A, E, F). The $\mathrm{O}-\mathrm{H}$ and $\mathrm{C}-\mathrm{H}$ stretching values (in $\mathrm{cm}^{-1}$ ) of the respective spectra obtained under standard and modified protocols have been given in table 3 . In the IR spectrum of native polysaccharide, a broadband of higher intensity has been observed at $3400 \mathrm{~cm}^{-1}$ due to $\mathrm{O}-\mathrm{H}$ stretching. The broadness of the band indicated the presence of

Table 3. IR interpretation of native and methylated polysaccharides

\begin{tabular}{|ccc|}
\hline Spectra & O-H band $\left(\boldsymbol{v}, \mathbf{c m}^{-1}\right)$ & $\mathbf{C}-H$ band $\left(\boldsymbol{v}, \mathbf{c m}^{-1}\right)$ \\
\hline A & 3400 & 2929 \\
B & 3450 & 2925 \\
C & 3445 & 2920 \\
D & 3450 & 2910 \\
E & 3394 & 2925 \\
F & - & 2925 \\
\hline
\end{tabular}



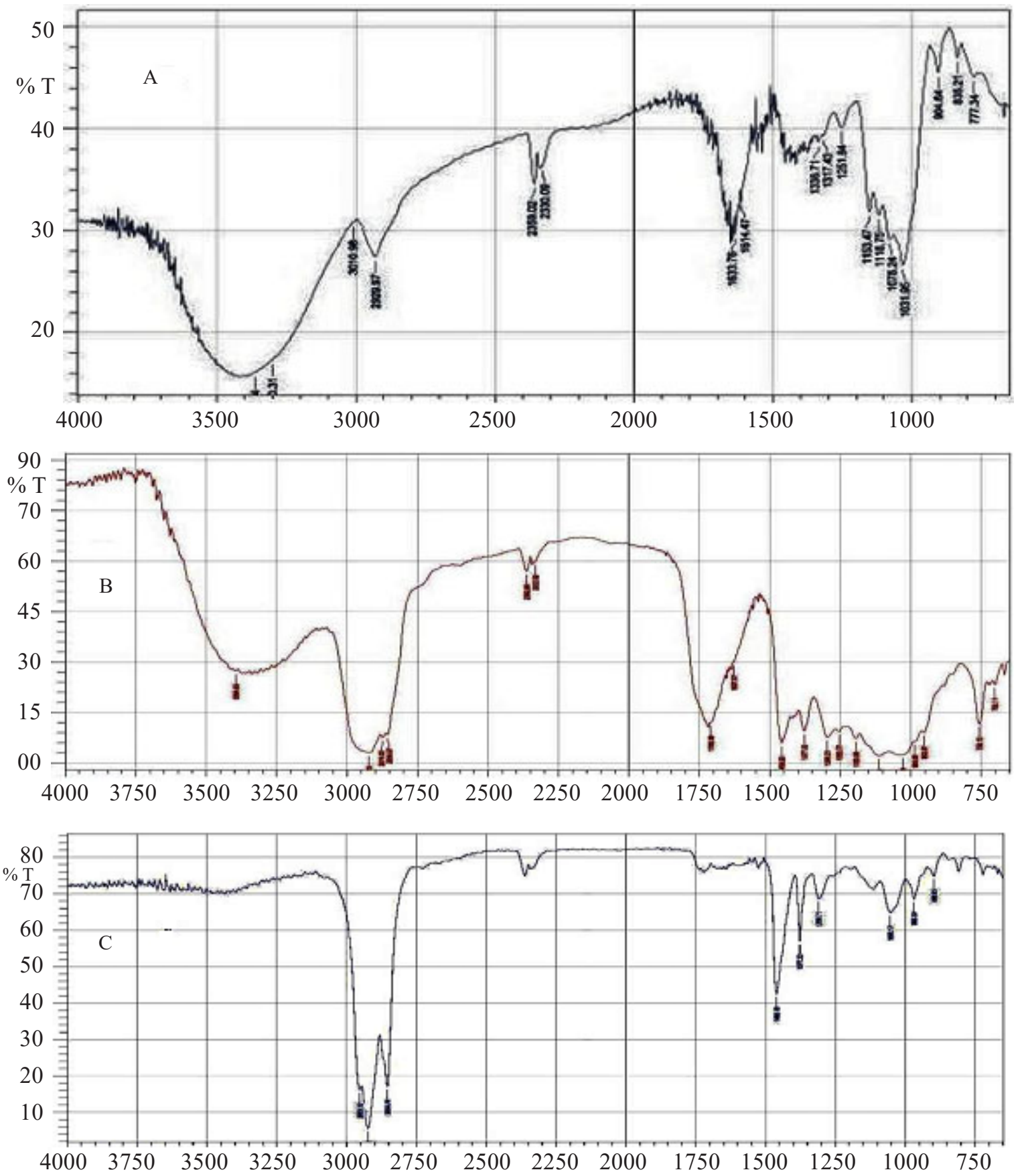

Figure 5. Methylation with modified method: A native polysaccharide; B one-time methylated; C two-times methylated polysaccharide. The band in -OH stretching region disappeared after 2 sequential methylations of sample thereby indicating permethylation

hydrogen bonding between $-\mathrm{OH}$ groups of polysaccharide chains. With an increasing degree of methylation, free hydroxyl groups were substituted by $-\mathrm{OCH}_{3}$ and hence contributed to a sharp band shifting to $3394 \mathrm{~cm}^{-1}$ is due to decreasing H-bonding in the polymer. Further, the intensity of the $\mathrm{C}-\mathrm{H}$ band was enhanced with increasing methyl groups. To sum up, permethylation of polysaccharide has been confirmed by the simultaneous loss of the $\mathrm{O}-\mathrm{H}$ band and increased intensity of the $\mathrm{C}-\mathrm{H}$ band at 2925 $\mathrm{cm}^{-1}$. 
Partially methylated alditol acetates (PMAA)

The permethylated AcTP and AcTPR polysaccharide samples were hydrolyzed by TFA, reduced with sodium borohydride, and then acetylated with acetic anhydride in the presence of pyridine to produce PMAA. The samples were then subjected to GC-EI-MS analysis. The fragmentation pattern of the peaks obtained in two chromatograms (native and reduced) was studied and linkage was interpreted. The PMAA chromatograms of native polymer illustrated 7 peaks corresponding to residues L-Rhap- $(1 \rightarrow$, L-Araf$(1 \rightarrow, \rightarrow$ 2)-L-Araf-( $1 \rightarrow$, D-Manp-( $1 \rightarrow$, D-Galp$(1 \rightarrow, \rightarrow 3)$-D-Galp- $(1 \rightarrow$ and $\rightarrow 3,6)$-D-Galp- $(1 \rightarrow$, while that of reduced polysaccharide sample displayed two additional peaks corresponding to $\rightarrow 4)$-D-GalAp- $(1 \rightarrow$ and $\rightarrow 4)-D-G l c A p-(1 \rightarrow$. The molar ratio of the residues is given in table 4 .

\section{Comparison of PMAA data and alditol acetate studies}

The molar ratio of constituent residues obtained in methylation analysis was compared to monosaccharide composition of AcTP obtained by alditol acetate analysis as given in table 5. PMAA data was found to be well corroborated by monosaccharide composition. The results reveal that the modified methylation method worked splendidly over standard protocol in linkage analysis. The results indicated complete methylation of acidic polymer in two successive methylations without any significant loss of material. It is clear from the data that AcTP comprised of backbone of arabinose and galactose as major monomers and rhamnose, mannose, galacturonic and glucuronic acids as minor monosaccharides. The polymer with repeating chain of $\rightarrow 3$ )-D-Galp$(1 \rightarrow$ and branching of $\rightarrow 2)$-L-Araf- $(1 \rightarrow$, at C6 of $\rightarrow 3)$-D-Galp- $(1 \rightarrow$ resembles type II arabinogalactans.

\section{Conclusion}

Cold water-soluble polysaccharide has been isolated from A. tortilis and subjected to standard methylation protocol that suffered several discrepancies, which were counteracted by incorporating optimal modifications in the former method. The results of standard and modified methylation methods were evaluated and the later has been found vividly superior over the former in terms of higher recovery of sample (minimum degradation \& losses) and greater efficiency (less number of methylations required) that collectively provides more accurate and reliable data required

Table 4. Linkage analysis of reduced and unreduced AcTP polysaccharides

\begin{tabular}{|c|c|c|c|c|c|}
\hline$\Lambda^{\text {No. }}$ & $\begin{array}{l}\text { Methylated } \\
\text { residues }\end{array}$ & $\begin{array}{l}\text { Mol } \\
\text { Native }\end{array}$ & $\begin{array}{l}\text { ar ratio } \\
\text { Carboxyl } \\
\text { reduced }\end{array}$ & Linkage type & Major mass fragments $(\mathrm{m} / \mathrm{z})$ \\
\hline 1 & $2,3,4-\mathrm{Me}_{3}-\mathrm{Rha}$ & 1 & 1 & L-Rha $p$ - $(1 \rightarrow$ & $43,101,117,131,161,175,205$ \\
\hline 2 & $2,3,4-\mathrm{Me}_{3}$-Ara & 6 & 6 & $\begin{array}{l}\text { L-Araf }-(1 \rightarrow \\
205\end{array}$ & $43,45,58,71,87,101,117,129,145,161$, \\
\hline 3 & $3,5-\mathrm{Me}_{2}$-Ara & 28 & 28 & $\rightarrow 2)$-L-Araf $-(1 \rightarrow$ & $43,45,71,87,101,129,161,173,189$ \\
\hline 4 & 2,3,4,6- $\mathrm{Me}_{4}-\mathrm{Man}$ & 1 & 1 & $\begin{array}{l}\mathrm{D}-\mathrm{Man}_{p}-(1 \rightarrow \\
205\end{array}$ & $43,45,59,71,87,101,117,129,145,161$, \\
\hline 5 & $2,3,4,6-\mathrm{Me}_{4}-\mathrm{Gal}$ & 1 & 1 & D-Gal $p-(1 \rightarrow$ & $\begin{array}{l}43,45,59,71,87,101,117,129,145,161, \\
205\end{array}$ \\
\hline 6 & $2,4,6-\mathrm{Me}_{3}-\mathrm{Gal}$ & 3 & 3 & $\rightarrow 3)-\mathrm{D}-\mathrm{Gal}_{p}-(1 \rightarrow$ & $\begin{array}{l}43,45,71,87,99,101,117,129,161,201, \\
233\end{array}$ \\
\hline 7 & $2,4-\mathrm{Me}_{2}-\mathrm{Gal}$ & 6 & 6 & $\begin{array}{l}\rightarrow 3,6)-\mathrm{D}-\mathrm{Gal}_{p}-(1 \rightarrow \\
233,305\end{array}$ & $43,58,73,87,99,101,117,129,189,201$, \\
\hline 8 & $2,3,6-\mathrm{Me}_{3}-\mathrm{Gal}$ & 0 & 2 & $\begin{array}{l}\rightarrow 4)-\mathrm{D}-\mathrm{Gal}_{p}-(1 \rightarrow \\
233\end{array}$ & $43,45,71,87,99,101,113,117,129,173$ \\
\hline 9 & $2,3,6-\mathrm{Me}_{3}-\mathrm{Glc}$ & 0 & 2 & $\rightarrow 4)-\mathrm{D}-\mathrm{Glc}_{p}-(1 \rightarrow$ & $\begin{array}{l}43,45,71,87,99,101,113,117,129,173, \\
233\end{array}$ \\
\hline
\end{tabular}


Table 5. Comparison of alditol acetate and partially methylated alditol acetate

\begin{tabular}{|lccl|}
\hline Monosaccharides & $\begin{array}{c}\text { Alditol acetate } \\
\text { Mol. ratio }\end{array}$ & $\begin{array}{c}\text { Partially methylated } \\
\text { alditol acetate } \\
\text { Mol. ratio }\end{array}$ & Residues \\
\hline Rhamnose & 1 & 1 & L-Rhap- $(1 \rightarrow$ \\
Arabinose & 34 & 6 & L-Araf- $(1 \rightarrow$ \\
& & 28 & $\rightarrow$ 2)-L-Araf- $(1 \rightarrow$ \\
Mannose & 1 & 1 & D-Manp- $(1 \rightarrow$ \\
Galactose & 10 & 1 & D-Galp- $(1 \rightarrow$ \\
& & 3 & $\rightarrow 3)-D-G a l p-(1 \rightarrow$ \\
Galacturonic acid & 2 & 2 & $\rightarrow 3,6)-D-G a l p-(1 \rightarrow$ \\
\end{tabular}

for meticulous structural characterization. By employing the modified protocol, one can obtain permethylated polysaccharide in a lesser number of steps with diminutive degradation and higher yields. Moreover, the polysaccharide isolated from $A$.tortilis was found to be an acidic polysaccharide and this fact further substantiates that unlike standard protocol, the modified method can be extended for structural characterization of neutral as well as acidic carbohydrate polymers as well. Further, linkage analysis of the polysaccharide of $A$. tortilis has been carried out for the first time, which may prove to be useful from a prospective of therapeutic applications. The knowledge of the chemical structure of the polysaccharide-based on appropriate methylation protocol is a basis for understanding its bioactivity and resultant enhanced pharmacological utilization.
Conflict of interest

The authors declare no conflict of interest.

\section{Acknowledgement}

The work in the present study has been carried out under the project entitled 'Structural studies and utilization of Acacia tortilis gum exudates'. The authors are grateful to the Director, Forest Research Institute (FRI), Dehradun for providing laboratory facilities. The authors are also thankful to Dr. J. C. Tewari, Principal Scientist (Forestry), CAZRI, Jodhpur, India for providing an authentic sample of Acacia tortilis subsp. raddiana (Sabi) Brenan gum exudate from Central Arid Zone Research Institute, Jodhpur research farm under the Network project on 'Harvesting, processing and value addition of Natural Resins and Gums'.

\section{References}

1. Hakomori, S.I. (1964). A rapid permethylation of glycolipid, and polysaccharide catalyzed by methylsulfinylcarbanion in dimethyl sulfoxide. The Journal of Biochemistry. 55(2): 205-208.

2. Aspinall, G.O. (1982). The polysaccharides. New York, Academic Press, Vol 1, pp. 45.

3. Purdie, T., Irvine, J.C. (1903). The alkylation of sugars. Journal of the Chemical Society, Transactions. 83: 1021-1037.

4. Haworth, W.N. (1915). III-A new method of preparing alkylated sugars. Journal of the Chemical Society, Transactions. 107: 8-16.

5. Kuhn, R., Trischmann, H., Löw, I. (1995). Zur permethylierung von zuckern und glykosiden. Angewandte Chemie. 67(1): 32-32.

6. Wallenfels, K., Bechtler, G., Kuhn, R., Trischmann, H., Egge, H. (1963). Permethylation of oligomeric and polymeric carbohydrates and quantitative analysis of the cleavage products. Angewandte Chemie. 2(9): 515-523.

7. Kuhn, R., Egge, H.J. (1963). Über Ergebnisse der Permethylierung der Ganlioside GI und GII. Chemische Berichte. 96(12): 3338-3348. 
8. Bredereck, H., Hagelloch, G., Hambsch, E.J. (1954). Notiz zur Darstellung der Oktamethyl saccharose. Chemische Berichte. 87(1): 35-37.

9. Corey, E.J., Chaykovsky, M. (1962). Dimethylsulfoxoniummethylide. Journal of the American Chemical Society. 84(5): 867-868.

10. Falconer, E., Adams, G. (1956). The aldobiouronic acids of hemicellulose B of oat hulls. Canadian Journal of Chemistry. 34(3): 338-344.

11. Barker, S., Stacey, M., Tipper, D. (1959). N, N-Methylation of Methyl 2-Acetamido-2-Deoxy$\alpha$-D-Glucopyranoside. Nature. 184(4700): 1718-1718.

12. Srivastava, H., Singh, P.P., Harshe, S., Virk, K. (1964). Methylation of polysaccharides with dimethyl sulphate. Tetrahedron Letters. 5(10): 493-498.

13. Geyer, R., Geyer, H., Kühnhardt, S., Mink, W., Stirm, S.(1982). Capillary gas chromatography of methylhexitol acetates obtalned upon methylation of N-glycosidically linked glycoprotein oligosaccharides. Analytical Biochemistry. 121(2): 263-274.

14. Parente, J.P., Cardon, P.,Leroy, Y., Montreuil, J., Fournet, B., Ricart, G. (1985). A convenient method for methylation of glycoprotein glycans in small amounts by using lithium methylsulfinyl carbanion. Carbohydrate Research. 141(1): 41-47.

15. Kvernheim, A.L. (1987). Methylation analysis of polysaccharides with butyllithium in dimethyl sulfoxide. Acta Chemica Scandinavica. 41: 150-152.

16. Ciucanu, I.; Kerek, F. (1984). A simple and rapid method for the permethylation of carbohydrates. Carbohydrate Research. 131(2): 209-217.

17. Rauvala H., Finne J., Krusius T., Kärkkäinen J., Järnefelt J. (1981). Methylation techniques in the structural analysis of glycoproteins and glycolipids. Advances in Carbohydrate Chemistry Biochemistry. New York, Academic Press. 38: 389-416.

18. Dell, A., Rogers, M.E., Thomas-Oates, J.E., Huckerby, T.N., Sanderson, P.N., Nieduszynski, I.A. (1988). Fast-atom-bombardment mass-spectrometric strategies for sequencing sulphated oligosaccharides. Carbohydrate Research. 179: 7-19.

19. Zahringer, U., Moll, H., Rietschel, E.T., Kraska, B., Imoto M., Kusumoto, S. (1990). GLCMS analysis of methylated 2-acetamido-2-deoxy-d-glucitol phosphates. Carbohydrate Research. 196: $147-155$.

20. Anonymous. (1985). The Wealth of India: a dictionary of Indian raw material. National Institute of Sciences Communication and Information Resources (NISCAIR) and Council of Scientific and Industrial Research (CSIR), New Delhi, Vol. 1, 1A (Revised), pp. 23.

21. Bisht, S., Kant, R., Kumar, V. (2013). $\alpha$-D-Glucosidase inhibitory activity of polysaccharide isolated from Acacia tortilis gum exudates. International Journal of Biological Macromolecules. 59: 214-220.

22. Linhardt, R.J., Bazin, H.G. (2001). Glycoscience: Chemistry and Chemical Biology I-III. Berlin, Heidelberg, Springer. 34: 63-74.

23. Kumar, V., Nagar, S. (2014). Studies on Tinospora cordifolia mono sugars and correlation analysis of uronic acids by spectrophotometric methods and GLC. Carbohydrate Polymers. 99: 291-296.

24. Lakhera, A., Kumar, V. (2017). Monosaccharide composition of acidic gum exudates from Indian Acacia tortilis ssp. raddiana (Savi) Brenan. International Journal of Biological Macromolecules. 94: 45-50.

25. Voiges, K., Adden, R., Rinken, M., Mischnick, P. (2012). Critical re-investigation of the alditol acetate method for analysis of substituent distribution in methyl cellulose. Cellulose. 19(3): 9931004.

26. Scott, R.W. (1979). Colorimetric determination of hexuronic acids in plant materials. Analytical Chemistry. 51(7): 936-941.

27. Taylor, R., Conrad, H.E. (1972). Stoichiometric depolymerization of polyuronides and glyco- 
saminoglycuronans to monosaccharides following the reduction of their carbodiimide-activated carboxyl group. Biochemistry. 11(8): 1383-1388.

28. Chaplin, M.F., Kennedy, J.F. (1994). Carbohydrate Analysis: A Practical Approach. New York, Oxford University Press. pp 82-85.

29. Hanisch, F.G. (1994). Methylation analysis of complex carbohydrates: Overview and critical comments. Biological Mass Spectrometry. 23(6): 309-312.

30. Harris, P.J., Henry, R.J., Blakeney, A.B., Stone, B.A. (1984). An improved procedure for the methylation analysis of oligosaccharides and polysaccharides. Carbohydrate Research. 127(1): 59-73.

31. Ciucanu, I., Caprita, R. (2007). Per- $O$-methylation of neutral carbohydrates directly from aqueous samples for gas chromatography and mass spectrometry analysis. Analytica Chimica Acta. 585(1): 81-85.

32. Ciucanu, I. (2006). Per- $O$-methylation reaction for structural analysis of carbohydrates by mass spectrometry. Analytica Chimica Acta. 576(2): 147-155. 